Article

\title{
Experimental Research of Gaseous Emissions Impact on the Performance of New-Design Cylindrical Multi-Channel Cyclone with Adjustable Half-Rings
}

\author{
Aleksandras Chlebnikovas ${ }^{1,2} \mathbb{D}$, Dainius Paliulis ${ }^{2}$, Kristina Kilikevičienè ${ }^{1}$ and Artūras Kilikevičius ${ }^{1, * \mathbb{D}}$ \\ 1 Institute of Mechanical Science, Faculty of Mechanics, Vilnius Gediminas Technical University, \\ J. Basanavičiaus g. 28, LT-03224 Vilnius, Lithuania; aleksandras.chlebnikovas@vilniustech.lt (A.C.); \\ kristina.kilikeviciene@vilniustech.lt (K.K.) \\ 2 Institute of Environmental Protection, Faculty of Environmental Engineering, Vilnius Gediminas Technical \\ University, Sauletekio al. 11, LT-10223 Vilnius, Lithuania; dainius.paliulis@vilniustech.lt \\ * Correspondence: arturas.kilikevicius@vilniustech.lt; Tel.: +370-67755819
}

check for

updates

Citation: Chlebnikovas, A.; Paliulis, D.; Kilikevičienè, K.; Kilikevičius, A Experimental Research of Gaseous Emissions Impact on the Performance of New-Design Cylindrical Multi-Channel Cyclone with Adjustable Half-Rings. Sustainability 2022, 14, 902. https://doi.org/ $10.3390 /$ su14020902

Academic Editors: Zhiqiang Geng, Yongming Han and Chong Chu

Received: 9 December 2021

Accepted: 11 January 2022

Published: 13 January 2022

Publisher's Note: MDPI stays neutral with regard to jurisdictional claims in published maps and institutional affiliations.

Copyright: (c) 2022 by the authors. Licensee MDPI, Basel, Switzerland. This article is an open access article distributed under the terms and conditions of the Creative Commons Attribution (CC BY) license (https:// creativecommons.org/licenses/by/ $4.0 /)$.

\begin{abstract}
Cyclones are widely used for separating particles from gas in energy production objects. The efficiency of conventional centrifugal air cleaning devices ranges from 85 to $90 \%$, but the weakness of many cyclones is the low collection efficiency of particles less than $10 \mu \mathrm{m}$ in diameter. The novelty of this work is the research of the channel-type treatment device, with few levels adapted for precipitation of fine particulate matter, acting by a centrifugal and filtration principle. Many factors have an impact on cyclone efficiency-humidity, temperature, gas (air) composition, airflow velocity and etc. Many scientists evaluated only the effect of origin and size of PM on cyclone efficiency. The effect of gas (air) composition and temperature, and humidity on the multi-channel cycloneseparator efficiency still demands contributions. Complex theoretical and experimental research on air flow parameters and the efficiency of a cylindrical eight-channel system with adjustable half-rings for removing fine-dispersive particles $(<20 \mu \mathrm{m})$ was carried out. The impact of air humidity and temperature on air flow, and gaseous smoke components on the removal of wood ashes was analyzed. The dusty gas flow was regulated. During the experiment, the average velocity of the cyclone was $16 \mathrm{~m} / \mathrm{s}$, and the temperature was $20-50^{\circ} \mathrm{C}$. The current paper presents experimental research results of wood ash removal in an eight-channel cyclone and theoretical methodology for the calculation of airflow parameters and cyclone effectiveness.
\end{abstract}

Keywords: cyclone; adjustable half-rings; particulate matter; efficiency; gaseous compounds; smoke

\section{Introduction}

Air pollution has increased during recent decades, especially due to the intense development of energy, industry and transport [1]. Air purification devices-cyclones-are usually used to remove particulate matter that forms inside energy-production objects during the process of combustion. They are among the cheapest air purification devices, but their principal disadvantage is their low particulate matter (less than $10 \mu \mathrm{m}$ in diameter) removal rate, which is especially obvious when strict requirements for the discharge of hazardous particles have to be met [1]. However, by improving the cyclone's structure, the isolation of finely divided particles up of to $10 \mu \mathrm{m}$ in diameter becomes possible [2-4].

Various methods are attempted in order to improve the cyclone's purification efficiencyusing a particle coagulation-inducing acoustic field, using a secondary air flow influx into the cyclone $[5,6]$.

A multi-channel cyclone allows higher efficiency than conventional cyclones. The structure of these devices is significantly improved, compared to the regular cyclone analogs, and meant for isolating particulate matter from an air-gas flow [7]. The combination of dust-polluted flow filtering and centrifugal purification is a new direction in 
centrifugal purification device improvement. These new generation multi-channel cyclones have been studied by scientists in many European countries [8-10].

Large-scale air purification devices were used to purify large volumes of air, which is economically unviable. A two- or three-level multi-channel cyclone can be used in such cases. In this device, there are two or three levels, one above the other. Each level has the same number of channels, and the partition between them separates the inflowing air into two equal parts. In diameter, the two- or three-level cyclone is the same as the single-level, but it is capable of purifying a larger volume of air because of its higher separation camera [4].

In general, the design methods of the conventional cyclone are based on the calculation of the size of the separation chamber, taking into account the rate of purified air. A distribution of airflows into peripheral and transitional in the inlet zone of each channel plays a particular role. The construction of a multi-channel cyclone consists of $\mathrm{n}$ channels having $n-1$ number of distribution zones. A cyclone is designed by calculating the amounts of the individual air flow rates sequentially for each of the cyclone channels and integrating them throughout the cyclone volume.

For experimental research, a new generation eight-channel cylindrical cyclone, inside of which air flows in a tangential direction through an inlet hollow and into a separation camera, where the circulating air flow is distributed in differently curved channels and is filtered through an air flow-a particulate matter of curvilinear channel gaps was chosen. Particulate matter (PM) is exposed to centrifugal and gravitational forces inside the channels, escapes through circular gaps, arranged in a segmental way, and goes to a conical bunker where most of the particulate matter is removed. The remaining finer particles return through the channel gaps into the active curvilinear channel zone, where they are further filtered and discharged to the conical bunker. After completing the purification cycle, the purified air flows out of the system through the outlet hole.

In most cases, particulate matter is formed in the air flow, together with the emission of $\mathrm{CO}$. Gaseous pollutants change the physical properties of the gas flow as well as the degree of precipitation of particulate matter. In particular, the concentration of gaseous pollutants is not taken into account, which causes discrepancies between the results of theoretical and experimental studies. The operating parameters of the cyclone are also affected by the temperature of the gas flow, which changes the viscosity of the gas. Therefore, in order to perform an accurate study, the ranges of the prevailing $\mathrm{CO}$ concentrations and gas flow temperatures must be evaluated, which is especially relevant for a new generation device as a multi-channel cyclone-separator.

The scientific-technical literature does not provide the air purification efficiency assessment formula for a multi-channel cyclone. An empirical formula, which evaluates the influence of the multi-channel cyclone's number of channels on the particulate matter's removal efficiency, can be found in the paper [11]. However, said formula only allows for calculating the overall efficiency of air purification, without taking into account the diameter of the particulate matter and the impact of gaseous compounds. A previous study found that the effectiveness of a cyclone depends on the particle humidity, ranged between 25 and $40 \%$ at a temperature of $20-30{ }^{\circ} \mathrm{C}$, and atmospheric pressure, varied between $99.8 \mathrm{kPa}$ and $102.0 \mathrm{kPa}$ [12]. The performance of a large-scale cyclone was analyzed using selective non-catalytic reduction technology at an up to $900{ }^{\circ} \mathrm{C}$ temperature. A change of efficiency was analyzed depending on the normalized stoichiometric ratio and inlet velocity of particles [13]. The condensation mechanism at different pressure drops of a square free-vortex cyclonic separator was researched. A low particle concentration of up to $500 \mathrm{mg} / \mathrm{m}^{3}$ increases the pressure drop by $10 \%$, although this could lead to improving the separation efficiency by up to $5-7 \%$ [14].

Mechanical, physical and chemical properties of particulate matter, as well as its dispersion and form, can have an impact on the efficiency of particulate matter removal inside the cyclone. The concentration of particulate matter also has a significant impact on the purification efficiency of the cyclone. Likewise, the structure and geometric parameters 
of the cyclone have an impact on the efficiency of capturing particulate matter. Moreover, the properties of gas (air) - temperature, viscosity and chemical structure-have an impact on the particulate matter's removal efficiency inside the cyclone. The influence of gas (air) on capturing particulate matter inside the cyclone manifests itself in two ways-it affects the viscosity of the gas mixture and, also, gaseous compounds can change the properties of particulate matter by causing their adhesion (or cohesion). The properties of particulate matter and the environment can change during the particulate matter's separation process. Due to the abundance of factors influencing the particulate matter's removal efficiency inside the cyclone, evaluating their impact on the cyclone's purification efficiency is a tremendously difficult task, which requires narrowing down the factors by accepting certain premises. This paper analyses the most common case, whereby an eight-channel cylindrical cyclone removes wood ash that forms in boiler houses during solid fuel combustion.

The purpose of the research is to evaluate, theoretically and experimentally, the impact of smoke gas compounds (pollutants) on the particulate matter's removal efficiency and aerodynamic parameters of the eight-channel cylindrical cyclone.

\section{Materials and Methods}

Smoke gas components (pollutants) can influence the efficiency of capturing particulate matter inside the new generation eight-channel cylindrical cyclone. The influence of gaseous compounds on the purification efficiency of the cyclone may vary according to the nature and concentration of the pollutant, and the temperature of gas (air). In order to evaluate the impact of gaseous pollutants on the cyclone's purification efficiency, experimental research on particulate matter's removal out of smoke (gas) was carried out.

Experiments were carried out in the following order: creating smoke (gas) and particulate matter sources; determining smoke gas component $\left(\mathrm{CO}, \mathrm{NO}, \mathrm{NO}_{2}, \mathrm{O}_{2}\right)$ concentrations and taking particulate matter samples for determining concentration; determining particulate matter concentration; determining purification efficiency of the cyclone; statistical evaluation of data.

\subsection{Devices and Equipment}

Experimental research was carried out using the following technique:

1. Aspirator M-822. Air traction velocity-0-10 L/min; air traction velocity margin of error- $\pm 6 \%$;

2. Testo 400 . Temperature measurement range -2 to $70{ }^{\circ} \mathrm{C}$; margin of error $- \pm 0.2{ }^{\circ} \mathrm{C}$; velocity measurement range $-1-30 \mathrm{~m} / \mathrm{s}$; margin of error- $\pm 0.05 \mathrm{~m} / \mathrm{s}$;

3. Testo $350 \mathrm{XL}$. Concentration measurement range: $\mathrm{O}_{2}-0$ to $25 \%$; $\mathrm{CO}-0$ to $10,000 \mathrm{ppm}$; $\mathrm{NO}-0$ to $3000 \mathrm{ppm} ; \mathrm{NO}_{2}-0$ to $500 \mathrm{ppm}$;

4. Differential pressure gauge DSM-1. Pressure measurement range- 0 to $20,000 \mathrm{kPa}$; margin of error- $\pm 5 \mathrm{~Pa}$;

5. Retsch RM200 mill;

6. Elution shaker Rotoshake RS 12;

7. Analytical scales KERN 770. Weight measurement range-0-210 g; measurement accuracy一 $\pm 0.00005 \mathrm{~g}$;

8. Drying cabinet. Maximum temperature $-200^{\circ} \mathrm{C}$;

9. Air compressor Cosmos. Working pressure-10 bar;

10. Ventilator ALTEKO. Engine power-2.2 kW;

11. A particle sprayer;

12. Chronometer Sekonda. Margin of error- $\pm 0.2 \mathrm{~s}$;

13. A sampling tube with a head;

14. An exicator;

15. AFA-VP-20 filters;

16. Tweezers;

17. A filtering cartridge for external filtering. 
Eight-channel cylindrical, one-, two- or three-level cyclones were used for experimental research. A cyclone with adjustable half-rings, positioned at 75/25-peripheral (recurrent) air flow volume is 50\% larger than that of the transit air-inflowing into other channels, was used for studies. Peripheral flow is additionally filtered inside the cyclone. The cyclone is set up in Vilnius Gediminas Technical University's Environmental Protection Technologies lab., Vilnius, Lithuania. The cyclone consists of air ducts made from PVC pipes, which connect the main elements of the system-air flow-generating axial fan and a new generation air purification device - of the eight-channel cylindrical cyclone. Pipes lead the purified air to a branch pipe that is connected to an air extraction system in the lab.

\subsection{Experimental Setup}

\subsubsection{Creation of a Smoke (Gas) and Particulate Matter Source}

In order to evaluate the impact of smoke (gas) on the particulate matter's removal efficiency inside the cyclone, two experimental studies were carried out: in the first experimental trial, wood ash was removed from clean $20^{\circ} \mathrm{C}$ air, and in the second experimental trial, wood ash was removed from $37^{\circ} \mathrm{C}$ smoke (gas). Smoke (gas) source was created by burning pine wood in a furnace (Figure 1).

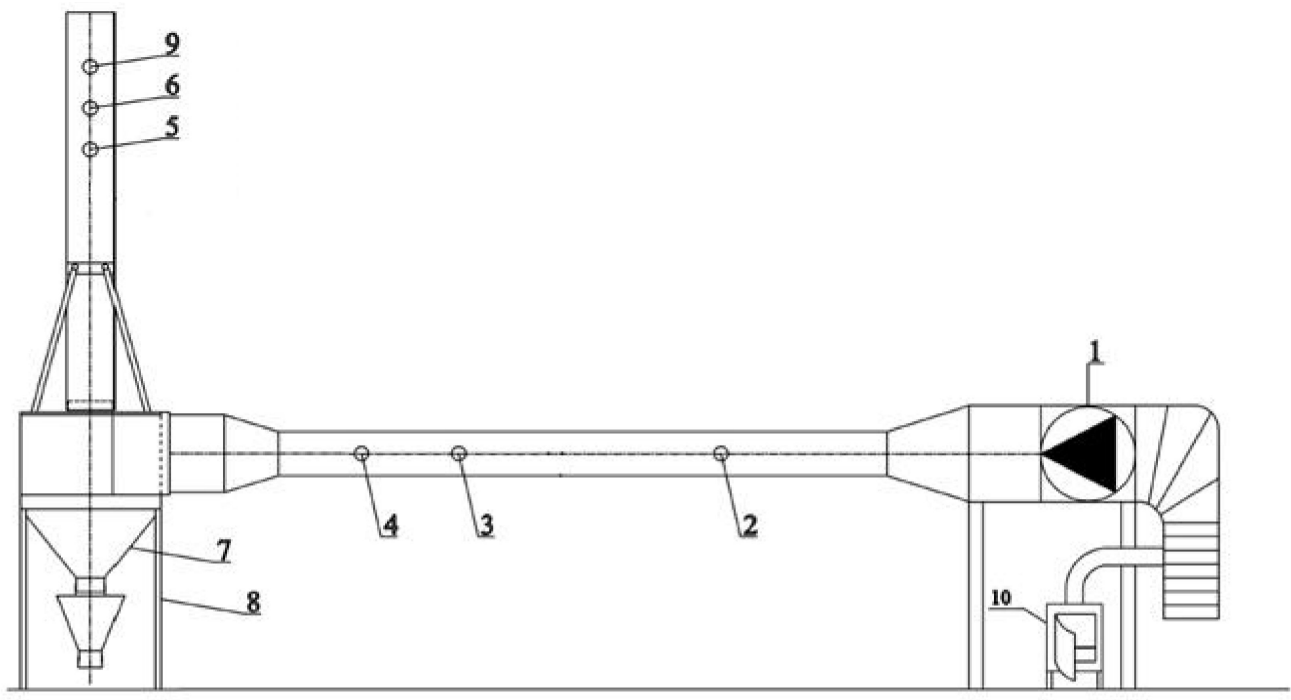

Figure 1. Particulate matter and smoke (gas) composition measurement scheme: (1) centrifugal fan, (2) particulate matter injection hole, (3) hole for pressure setting before the cyclone, (4) hole for particulate matter concentration setting before treatment, (5) hole for pressure setting after the cyclone, (6) hole for particulate matter concentration setting after treatment, (7) trapped particulate matter hopper, (8) the supporting construction, (9) hole for chemical compounds concentration setting, (10) furnace.

During the experimental tests, the CO concentration was $4000-31,000 \mathrm{mg} / \mathrm{m}^{3}$, NO concentration was $900-2000 \mathrm{mg} / \mathrm{m}^{3}$, and $\mathrm{O}_{2}$ concentration was $20.65-20.92$ percent. Concentration of $\mathrm{NO}_{2}$ and $\mathrm{SO}_{2}$ was 0 to 2 ppm, which is why they weren't evaluated.

Particulate matter source was created by spraying particulate matter into an air duct after the ventilator, in the direction of the flow with a sprayer connected to a compressor that creates a 10 bar pressure airflow. Once in the air duct, particles are exposed to an airflow, created by the ALTEKO centrifugal ventilator. Before spraying wood ash, a required position of the lever is set on the control unit. The lever controls the ducted fan's energy usage and, at the same time, yield of the air flow volume inside the air duct is decreased. During the experimental trials, PM (particulate matter) concentration and smoke (gas) composition inside the air duct system were examined. Concentration of wood ash was $5 \mathrm{~g} / \mathrm{m}^{3}$. Properties of the wood ash: bulk density $-710 \mathrm{~kg} / \mathrm{m}^{3}$; overall density $-800-900 \mathrm{~kg} / \mathrm{m}^{3}$. 


\subsubsection{Aerodynamic Parameters}

Experimental research on air flow velocity was carried out in an air duct system, where measurement points were selected in a straight section, thus avoiding disturbances in the stabilized gas flow, inside the cyclone's structure, in the lid, and in the partition between the special $6 \mathrm{~mm}$ gaps drilled amid the levels. In order to make the measurements, holes were drilled in the selected point inside the air duct. Measurement points' scheme is presented in Figure 2.

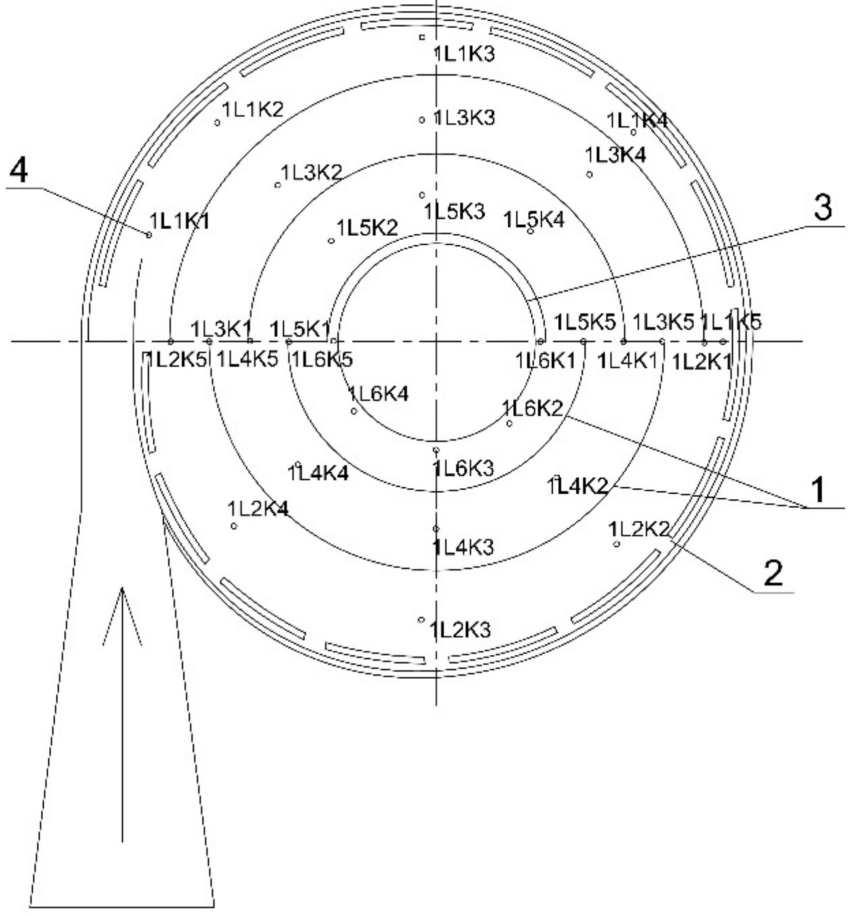

(a)

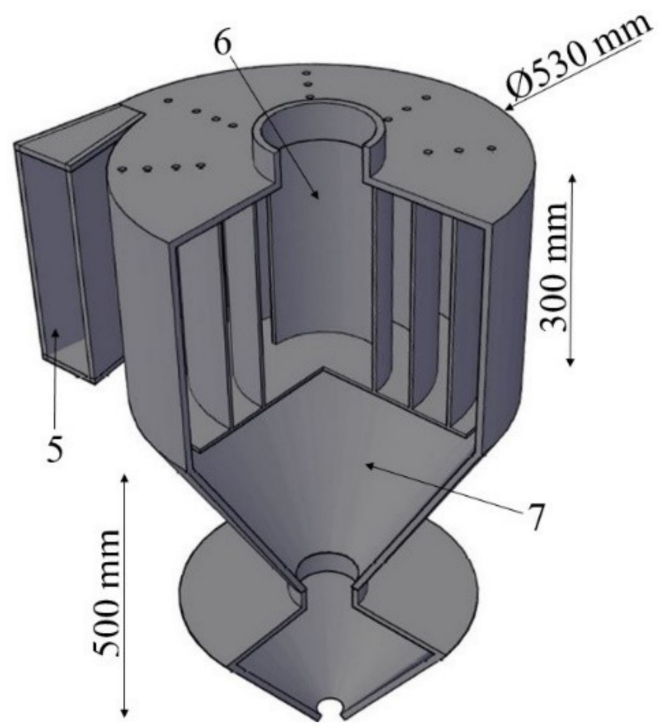

(b)

Figure 2. A scheme of measurement points' arrangement inside the channels of the device; (a) top view and (b) 3D view; (1) curvilinear half-rings, (2) sectional gaps, (3) air outflow opening, (4) measurement point (here $1 \mathrm{~L}-1$ st level; $1 \mathrm{~K}$-1st channel; 1 -1st point in the correspondent channel), (5) and (6) air flow inlet and outlet, (7) cyclone's hopper.

Air flow velocity measurement was carried out in accordance with the Lithuanian Environmental Normative Document, LAND 27-98/M-07. Measurement of gas flow velocity and volume in the duct (herein after, LAND 27). Gas flow velocity inside the channels of the cyclone was measured with a dynamic Piton pipe connected to the Testo 400 device. In order to properly evaluate the movement of the flows, five measuring points were selected in each of the cyclone's channels.

Aerodynamic resistance is measured with a differential pressure gauge DSM-1. For the purpose of the research, a case, when the maximum particulate matter's removal efficiency is reached in not only one, but also two and three-level eight-channel cylindrical cyclone, i.e., air flows at the velocity of $16 \mathrm{~m} / \mathrm{s}$, was chosen.

\subsubsection{Pollutant Concentration and Treatment Efficiency}

Preparation of the PM concentration measurement for the experimental research consisted of: installing the ventilator, setting proper air flow velocity, selecting an appropriate lever position on the control unit, and connecting measurement devices. For the measurement of PM concentration inside the air ducts, a point in a straight section of the air duct with a stable, undisturbed gas flow was selected. Wood ash that formed in energy objects during combustion was chosen for the experimental efficiency measurement re- 
search on the eight-channel cylindrical cyclone, designed for purifying polluted air. Before conducting the research, wood ash was heated up in a drying furnace at $100-105^{\circ} \mathrm{C}$ until its weight stabilized and moisture evaporated. Particulate matter was pulverized in a Retsch RM200 mill. Dried particulate matter was sifted through screens with an elution shaker Rotoshake RS 12. Screens with 20 and $50 \mu \mathrm{m}$ pores were used for the research. Only 0-20 $\mu \mathrm{m}$ diameter particulate matter was used in the experimental research. Before the research, special branch pipes, $7 \mathrm{~mm}$ in interior diameter and $10 \mathrm{~mm}$ in exterior diameter, fitted onto the inflowing and outflowing air ducts, connected to each other, and to the air filter cartridges with rubber hoses. Particulate matter-deterring AFA-VP-20 filters were installed in the cartridges. The second hose connected the head of the cartridge with the aspirator's inlet for suctioned air. Purification efficiency of wood ash-polluted air was calculated in accordance with the known suctioned air volume and the mass differences between filters. When taking disposable samples, isokinetic conditions were maintained, when the velocity of the air pumped through the filter was equal to the velocity of the adversative flow, in order to determine the concentration of particulate matter. The velocity was made uniform with conical heads, which were selected considering the velocity of both - the flow and the pumped air. Retainer of the filter was directed towards the air flow.

Weighing method was selected for measuring the concentration of particulate matter. The principle of this method is that particulate matter is held up in a filter, a particular volume of air gets pumped through it and the mass of the particulate matter is determined by the weighing method. Relative margin of error for the method did not exceed $\pm 25 \%$ (Lithuanian Environmental Normative Document, LAND 28-98/M-08. Weight method (herein after, LAND 28)). Before taking a sample, the filter was weighed on analytical scales. Prior to that, it was held in a room for $1 \mathrm{~h}$ where it was weighed. Air, examined to determine the concentration of particulate matter, was pumped through the filter at the velocity of $10 \mathrm{~L} / \mathrm{min}$. Then the mass of particulate matter was measured in a laboratory.

Before weighing, the filter was held in the room where it was going to be weighed for no less than one hour. Particulate matter concentration was measured and the volume of air pumped through the filter under normal conditions, according to formulas provided in LAND 28, was recalculated. Particulate matter concentration was measured before and after cyclonic separation. With reference to the data of the research, efficiency of particulate matter removal inside the eight-channel cylindrical cyclone was measured.

Measurements of the gas component $\left(\mathrm{CO}, \mathrm{NO}, \mathrm{NO}_{2}, \mathrm{O}_{2}\right)$ concentrations were made with TESTO-350 M/XL. Molar volume of gas $(\mathrm{L} / \mathrm{mol})$ was established, with reference to Lithuanian Environmental Normative Document, LAND 43-2013. Approval of emissions' standards for combustion plants (herein after, LAND 43), smoke gas component (CO, $\mathrm{NO}, \mathrm{NO}_{2}$ ) volume concentrations (ppm), determined with TESTO-350 M/XL device, were recalculated into weighted concentration $\mathrm{mg} / \mathrm{m}^{3}$ (when $\mathrm{O}_{2}$ concentration is equal to $6 \%$ of solid fuel).

A statistical analysis was performed to evaluate the results of experimental research. Every measurement was made five times in order to avoid systematic error and to make the error of the average as small as possible. Averages, standard deflections, dispersions and statistical criteria were calculated. Correlation between the measured quantities was evaluated by using the Pearson's correlation coefficient $[15,16]$. Statistical calculations were carried out with Microsoft Excel.

\subsection{Theoretical Research}

\subsubsection{Methodology of Theoretical Evaluation of Aerodynamic Parameters in the} Multi-Channel Cyclone-Separator

The following research methodology was prepared by taking advantage of the experience of foreign researchers and with respect to the normative Lithuanian Environmental Protection documents. After analyzing the experimental, theoretical research on the traditionally structured cyclone's parameters, and the results of other researchers' experiments, a methodology was created to evaluate the impact of gaseous compounds (pollutants) on 
the particulate matter's removal efficiency of the new generation eight-channel cylindrical cyclone.

Firstly, the main parameters characterizing this flow-dry and wet gas flow density, dynamic and kinematic viscosity, and dew point value-were calculated. The change was assessed by assuming the environment in question as a mixture of vapor and gas flow, the predominant temperature of this environment, and the relative humidity. The maximum dependences of the relative humidity of the gas flow and the density of the wet gas flow on the temperature of the aggressive gas flow were determined theoretically. A mathematical expression was calculated for the calculation of the relative humidity of the aggressive gas flow, depending on the aggressive gas flow temperature [17,18].

In the general case, the gas flow density is calculated using Equation (1), taking into account the change in partial pressure of the dry gas flow, assuming the existing relative humidity and temperature. The mathematical expression is:

$$
\rho_{\text {g.f. }}=\frac{P_{\text {d.g.f. }}}{R_{\text {d.g.f. }} \cdot T_{\text {g.f. }}}+\frac{\varphi_{\text {g.f. }} \cdot 6.1078 \cdot e^{\frac{17.08085 . t}{234.175+t}}}{R_{\text {w.v. }} \cdot T_{\text {g.f. }}}
$$

where $\rho_{g . f .}$ - a density of the gas flow, $\mathrm{kg} / \mathrm{m}^{3} ; P_{\text {d.g.f. }}$ - partial pressure of the dry gas flow, $\mathrm{Pa} ; R_{\text {d.g.f. }}$ - a constant of the dry gas flow; $T_{\text {g.f. }}$-absolute temperature of the gas flow, $\mathrm{K}$; $\varphi_{\text {g.f. }}$-relative humidity of the gas flow, $\%$; $t$-temperature of gas flow, ${ }^{\circ} \mathrm{C} ; R_{\text {w.v. }}$ - constant of the water vapor.

A specially adapted mathematical expression for the calculation of the aggressive gas flow density at $20^{\circ} \mathrm{C}, 37^{\circ} \mathrm{C}, 50{ }^{\circ} \mathrm{C}, 100{ }^{\circ} \mathrm{C}, 120^{\circ} \mathrm{C}$ and $200{ }^{\circ} \mathrm{C}$ aggressive gas flow temperature, based on the theoretical research, was derived. Additional temperatures were taken to present more precise changes of parameter.

Theoretical mathematical expressions for the calculation of the moving gas flow velocity of an improved multi-channel cyclone were used to estimate the change in dynamic pressure and the magnitude of the gas flow density. However, in the case of aggressive gas flow, the dry and wet gas flow pressures and the effect of water vapor and temperature on the gas flow viscosity must be additionally evaluated. Theoretical research has used a constructed full mathematical expression (Equation (2)), which is complex.

The flow velocity of the aggressive gas is affected by relative humidity and gas flow temperature. According to extended expression (Equation (3)), it can be seen that the gas flow velocity is directly proportional to the dynamic pressure, $P_{d y n H_{2} \mathrm{O}}$, and inversely proportional to the aggregate gas flow rate, $g_{t}$.

$$
U=\sqrt{\frac{2 \cdot g \cdot P_{d y n}}{\left(\frac{P_{\text {s.d.s. }}}{R_{\text {s.d.s. }} T_{\text {d.s. }}}+\frac{6.112 \cdot e\left(\frac{17.67 \cdot t}{243.5+t}\right) \cdot \varphi_{\text {d.s. }}}{R_{\text {v.g. }} \cdot T_{\text {d.s. }}}\right)}}
$$

Here, $U$-a velocity of gas flow in cyclone channel, $\mathrm{m} / \mathrm{s} ; g$ - an acceleration of free fall, $\mathrm{m} / \mathrm{s}^{2} ; P_{d y n}$ - a dynamic pressure of the gas flow, $\mathrm{mmH}_{2} \mathrm{O} ; P_{\text {d.g.f. }}$ - a partial pressure of dry gas flow, $\mathrm{Pa}$, which is equal to $101,325 \mathrm{~Pa} ; R_{\text {d.g.f. }}$ - constant of dry gas flow; $T_{\text {g.f. }}$ - a total temperature of gas flow, $\mathrm{K} ; t_{\text {g.f. }}$ - - temperature of gas flow, ${ }^{\circ} \mathrm{C} ; \varphi_{\text {g.f. }}$ - a relative humidity of gas flow, \%; $R_{w . v .}$ - a constant of water vapor. This equation can be applied when the temperature of the gas flow is $t_{g . f .}=50{ }^{\circ} \mathrm{C}$ and the interval of the relative humidity is $\varphi_{\text {d.s. }}=0-95 \%$.

The value of $g_{t}$ is directly proportional to the atmospheric pressure and inversely proportional to the temperature of the aggressive gas flow. This theoretical research assumes that the atmospheric pressure does not change and is equal to atmospheric pressure.

$$
U=\sqrt{\frac{2 \cdot g_{t} \cdot P_{d y n}}{\rho_{\text {d.s.n.s. }}=0.359 \cdot 1.292 \cdot \frac{P_{a t m .}}{273+t_{\text {d.s. }}}}}
$$


Here, $U$ - a gas flow velocity in cyclone, $\mathrm{m} / \mathrm{s} ; g$-an acceleration of free fall, $\mathrm{m} / \mathrm{s}^{2}$; $P_{d y n}$ - a dynamic pressure of the gas flow, $m m H_{2} \mathrm{O} ; \rho_{\text {g.f.n.c. }}$-a density of gas flow in normal conditions, $\mathrm{kg} / \mathrm{Nm}^{3} ; P_{a t m}$. - an atmospheric pressure, $\mathrm{mmHg} ; t_{g . f}$ - - temperature of gas flow, ${ }^{\circ} \mathrm{C}$.

Specially adapted mathematical expressions are derived to calculate the velocity of aggressive gas flow at the beginning of the first new design cyclone channel as a function of the humidity of the aggressive gas flow and separately from the temperature.

In order to evaluate the impact of gas on the particulate matter removal efficiency of the multi-channel cyclone, certain assumptions have to be made.

The following environmental properties exert an influence on the particulate matter removal efficiency of the multi-channel cyclone-temperature of gas (air); composition of gas (air); properties of gas (air).

During the theoretical evaluation, the following assumptions were made: pressure is equal to atmospheric pressure (1 atmosphere); particulate matter interaction is not taken into account; particulate matter adhesion to the surface-cohesion-is not taken into account; physical and chemical properties of particulate matter (except for bulk density) are not taken into account; the purified gas (air) is dry; water vapor and gaseous components in smoke (gas) do not cause the adhesion of particulate matter; the impact on air purification of inert gas (except argon) and other gases, which have a very small concentration in smoke (gas/air), was not evaluated.

In order to evaluate the impact of gaseous components and temperature on the particulate matter removal efficiency inside the cyclone, a theoretical evaluation was made for the case, when air temperature is $37-120^{\circ} \mathrm{C}$ and the volume concentration of $\mathrm{CO}$ in smoke (gas) is up to $31,000 \mathrm{mg} / \mathrm{m}^{3}$.

A new generation eight-channel cylindrical cyclone built in Vilnius Tech Environmental Protection Institute, Vilnius, Lithuania was selected for the theoretical research to evaluate the dispersed particulate matter removal efficiency. The scientific-technical literature does not supply the formulas required for making theoretical calculations of the impact of gaseous compounds on the air purification efficiency of the multi-channel cyclone, except for the empirical formula allowing for general air purification efficiency calculations. For that reason, the value $d_{50}\left(d_{50}\right.$ - diameter of particulate matter, which is purified inside the cyclone at $50 \%$ efficiency) was chosen for the theoretical evaluation of the cyclone's air purification efficiency. Without an impactor, there was no way of measuring the $d_{50}$ value during the experimental research. $d_{50}$ value calculation algorithm (stages) was used when particulate matter is separated from smoke (gas).

Smoke (gas) mixture-forming components was defined, smoke (gas) temperature was defined, smoke (gas) density was calculated, concentrations of the smoke (gas) mixtureforming components were accepted or measured, dynamic viscosity of the smoke (gas) mixture-forming components was calculated, dynamic viscosity of the smoke (gas) mixture was calculated, and parameter $\mathrm{d}_{50}$ was calculated.

2.3.2. Methodology of Theoretical Evaluation of Impact of the Gas (Air) Temperature's and Smoke (Gas) on the Purification Efficiency of the Multi-Channel Cyclone

After analyzing the scientific-technical literature, it was determined that the theoretical evaluation of the overall purification efficiency of the multi-channel cyclone is a difficult task, therefore, the $d_{50}$ value $\left(d_{50}\right.$ is equal to $50 \%$ efficiency of particulate matter removal inside the cyclone) is usually the one that is measured. Two cases were taken for the theoretical evaluation of the cyclone's efficiency (in both cases, the reference point is $20{ }^{\circ} \mathrm{C}$ temperature): water when air temperature is equal to $37^{\circ} \mathrm{C}$; water when air temperature is equal to $120^{\circ} \mathrm{C}$.

The calculation algorithm (in stages) of the value $d_{50}$ when particulate matter is removed from the air: air composition and concentrations of air components are defined; air temperature is defined and dynamic viscosity of air is calculated; and parameter $\mathrm{d}_{50}$ is calculated. The new generation eight-channel cylindrical cyclone particulate matter 
removal efficiency was analyzed when particulate matter was emitted into the gas (air) at $37^{\circ} \mathrm{C}$ and $120{ }^{\circ} \mathrm{C}$. Air of the atmosphere is made up of these components (in percentages of total volume): $\mathrm{N}_{2}(78.1 \%), \mathrm{O}_{2}(20.95 \%), \mathrm{Ar}(0.93 \%), \mathrm{CO}_{2}(0.03 \%), \mathrm{He}, \mathrm{Kr}, \mathrm{Ne}, \mathrm{Xe}$ and others around $0.01 \%$.

Particulate matter can be removed inside the cyclone at different air temperatures. Theoretical evaluation was made at $37^{\circ} \mathrm{C}$ and $120^{\circ} \mathrm{C}$ air, given the pressure of 1 atmosphere. Wood ash was removed from clean air at $20^{\circ} \mathrm{C}$, and at $37{ }^{\circ} \mathrm{C}$ from smoke (gas). $120{ }^{\circ} \mathrm{C}$ temperature was chosen because it is typical for the cyclone, which is used for capturing wood ash that forms during combustion of biofuel. Changes in air temperature affected its dynamic density, which had an impact on the purification efficiency of the cyclone. Dynamic viscosity values of air were calculated at $37^{\circ} \mathrm{C}$ and $120^{\circ} \mathrm{C}$. Results of the dynamic viscosity calculations are presented in Table 1.

Table 1. $\mathrm{d}_{50}$ values, at the gas temperature of $37^{\circ} \mathrm{C}$ and $120^{\circ} \mathrm{C}$.

\begin{tabular}{cccc}
\hline No. & Gas Temperature, ${ }^{\circ} \mathbf{C}$ & CO Concentration, $\mathbf{g} / \mathbf{m}^{\mathbf{3}}$ & $\mathbf{d}_{\mathbf{5 0}, \boldsymbol{\mu m}}$ \\
\hline 1 & 37 & 4 & 5.097 \\
2 & 37 & 17 & 5.110 \\
3 & 37 & 31 & 5.125 \\
4 & 120 & 0.532 & 5.449 \\
\hline
\end{tabular}

The last stage is the calculation of particulate matter diameter that is removed at $50 \%$ efficiency $\left(d_{50}\right)$ from $37{ }^{\circ} \mathrm{C}$ and $120{ }^{\circ} \mathrm{C}$ air. Inside the $50 \%$ efficient $\left(d_{50}\right)$ cyclone, diameter of the removed particulate matter was calculated according to the following formula:

$$
\mathrm{d}_{50}=d_{50}^{L} \sqrt{\frac{D \cdot \rho_{D_{L}} \cdot \mu \cdot v_{L}}{D_{L} \cdot \rho_{D} \cdot \mu_{L} \cdot v}}
$$

where $d_{50}^{L}$-a diameter of particles precipitated at $50 \%$ probability in the comparative cyclone, $\mu \mathrm{m} ; D_{L}-$ a diameter of the comparative cyclone, $\mathrm{m} ; \mathrm{D}-$ a diameter of the tested multi-channel cyclone, $\mathrm{m} ; \rho_{D_{L}}$-a particle density inside the comparative cyclone, $\mathrm{kg} / \mathrm{m}^{3}$; $\rho_{D}$ - a particle density in the tested multi-channel cyclone, $\mathrm{kg} / \mathrm{m}^{3} ; \mu_{L}$-a dynamic gas viscosity in the comparative cyclone, Pa.s; $\mu$-a dynamic gas viscosity in the tested multichannel cyclone, $\mathrm{Pa} \cdot \mathrm{s} ; v_{L}$-average velocity of gas in the comparative cyclone, $\mathrm{m} / \mathrm{s} ; \mathrm{v}$ average velocity of gas in the tested multi-channel cyclone, $\mathrm{m} / \mathrm{s}$.

Diameter of the particulate matter, removed at 50\% efficiency $\left(d_{50}\right)$ inside the eightchannel cylindrical cyclone at the temperature used in the studies was calculated according to Equation (1). It is pre-defined that $d_{50}^{L}$ is equal to $5.0 \mu \mathrm{m}, D_{L}=D=0.502 \mathrm{~m}$, $\rho_{D_{L}}=\rho_{\mathrm{D}}=710 \mathrm{~kg} / \mathrm{m}^{3}, v_{L}=v=16 \mathrm{~m} / \mathrm{s} ; \mu_{L}=18.232 \cdot 10^{-6} \mathrm{~Pa} \cdot \mathrm{s}$ (at $20^{\circ} \mathrm{C}$ ), while $\mu$ is dependent on the temperature used in the studies (Table 1 ).

2.3.3. Methodology of Theoretical Evaluation of the Impact of Smoke (Gas) on the Purification Efficiency of the Multi-Channel Cyclone

In order to assess the value $d_{50}$ theoretically, the composition of smoke (gas) has to be defined. The cyclone can be used to remove wood ash expelled from boiler houses. In order to assess the theoretical impact that smoke (gas) exerts on the wood ash removal efficiency inside the cyclone, theoretical calculations were made for 4 cases: when gas temperature was $37^{\circ} \mathrm{C}, \mathrm{CO}$ concentration reached $31,000 \mathrm{mg} / \mathrm{m}^{3}, \mathrm{O}_{2}$ concentration was $20.92 \%$, and NO concentration was $2000 \mathrm{mg} / \mathrm{m}^{3}$; when gas temperature was $37{ }^{\circ} \mathrm{C}, \mathrm{CO}$ concentration reached $17,000 \mathrm{mg} / \mathrm{m}^{3}, \mathrm{O}_{2}$ concentration was $20.80 \%$, and $\mathrm{NO}$ concentration was $1200 \mathrm{mg} / \mathrm{m}^{3}$; when gas temperature was $37^{\circ} \mathrm{C}, \mathrm{CO}$ concentration reached $4000 \mathrm{mg} / \mathrm{m}^{3}, \mathrm{O}_{2}$ concentration was $20.65 \%$, and NO concentration was $900 \mathrm{mg} / \mathrm{m}^{3}$; when the temperature of wood in the boiler house, stoked by wood, reached $120{ }^{\circ} \mathrm{C}, \mathrm{CO}$ concentration reached $532.4 \mathrm{mg} / \mathrm{m}^{3}$, NO concentration was $352.1 \mathrm{mg} / \mathrm{m}^{3}$, and $\mathrm{O}_{2}$ concentration in smoke was $7.9 \%$ (this data was obtained by carrying out research on the biofuel combustion product 
concentrations in the boiler house). $\mathrm{d}_{50}$ measurement for the first case, when gas temperature was $37{ }^{\circ} \mathrm{C}, \mathrm{CO}$ concentration was $31,000 \mathrm{mg} / \mathrm{m}^{3}, \mathrm{O}_{2}$ concentration was $20.92 \%$, and $\mathrm{NO}$ concentration was $2000 \mathrm{mg} / \mathrm{m}^{3}$, follows.

During the combustion of solid fuel (wood), the following primary pollutants are emitted into the gas: particulate matter, $\mathrm{CO}, \mathrm{NO}_{\mathrm{x}}, \mathrm{CO}_{2}, \mathrm{SO}_{2}$, and also $\mathrm{CH}_{4}, \mathrm{~N}_{2} \mathrm{O}, \mathrm{NMVOCs}$ (non-methane volatile organic compounds). Emission rates in Lithuania, when firewood is burned to obtain energy, are: $\mathrm{CO}_{2}-102.0 \mathrm{~kg} / \mathrm{GJ} ; \mathrm{CO}-0.16 \mathrm{~kg} / \mathrm{GJ} ; \mathrm{SO}_{2}-0.13 \mathrm{~kg} / \mathrm{GJ} ; \mathrm{NO}_{\mathrm{x}}-$ $0.13 \mathrm{~kg} / \mathrm{GJ}$; NMVOCs-0.048 kg/GJ; $\mathrm{CH}_{4}-0.032 \mathrm{~kg} / \mathrm{GJ} ; \mathrm{N}_{2} \mathrm{O}-0.004 \mathrm{~kg} / \mathrm{GJ}$. Experimental research determined that the concentration of $\mathrm{NO}_{2}$ and $\mathrm{SO}_{2}$ was $0-2 \mathrm{ppm}$. Concentrations of $\mathrm{CH}_{4}, \mathrm{~N}_{2} \mathrm{O}$ and NMVOCs were not measured and, because the theoretical factors of the emissions of these compounds were several times fewer than $\mathrm{CO}$ or $\mathrm{NO}_{\mathrm{x}}$, these gaseous compounds were not included in the theoretical evaluation. Furthermore, smoke (gas) is comprised of components found in air: $\mathrm{O}_{2}, \mathrm{~N}_{2}, \mathrm{Ar}$, and other inert gases (the impact of other inert gases on the efficiency of cyclone separation was not evaluated theoretically because of their small concentration).

During the experimental studies, smoke (gas) temperature was $37^{\circ} \mathrm{C}$. When purifying smoke from a boiler house that burns wood, the temperature is $150{ }^{\circ} \mathrm{C}$ before entering the economizer, and $46-60^{\circ} \mathrm{C}$ after leaving the economizer. Assuming that the density of smoke (gas) is roughly equal to that of air, gas density was calculated. Concentrations of smoke (gas) mixture components are either calculated or pre-defined.

Emission levels in energy objects that burn biofuel are regulated by LAND 43-2013. It sets the permissible thresholds for $\mathrm{CO}$, particulate matter and $\mathrm{NO}_{\mathrm{x}}$ of emissions. Permissible threshold values for $\mathrm{CO}_{2}, \mathrm{SO}_{2}, \mathrm{CH}_{4}, \mathrm{~N}_{2} \mathrm{O}$ and NMVOCs concentrations are not regulated in Lithuania. Concentrations of $\mathrm{NO}_{x}$ are equated to concentrations of $\mathrm{NO}$ because almost no $\mathrm{NO}_{2}$ is released when burning wood. Concentration of $\mathrm{O}_{2}$ was $20.92 \%$ (percentage of volume) during the experimental trials. Concentration of $\mathrm{CO}_{2}$ (in percentage of volume) was calculated by assuming that the concentration of $\mathrm{O}_{2}$ was $20.92 \%$. Only a small amount of airborne nitrogen turns into nitric oxide, and argon remains inert during combustion. Therefore, it was accepted that concentrations of $\mathrm{N}_{2}$ and Ar in smoke (gas) are equal to their concentrations in dry air.

Concentrations of gaseous compounds $\left(\mathrm{CO}_{2}, \mathrm{CO}, \mathrm{NO}_{\mathrm{x}}, \mathrm{O}_{2}\right.$, etc. $)$ in emissions depend on the composition and moisture of the fuel, temperature of combustion, structure of the boiler, and other factors, which is why the calculated concentrations of gaseous compounds are only approximate. It was determined that among the pollutants in smoke (gas), $\mathrm{CO}$ reaches the highest concentration, $\mathrm{CO}_{2}$ has slightly smaller concentration, and $\mathrm{NO}$ has the smallest. The proportion of every smoke (gas) mixture-forming component $\left(A_{n}\right)$ in the mixture was measured in percentages of mass. After that, their molar mass in the mixture was calculated (fractions of one). Knowing the molar concentrations of smoke (gas) components, molecular mass of the smoke (gas) mixture was calculated. It was equal to $28.939 \mathrm{~g} / \mathrm{mol}$. The estimated molecular mass of the smoke (gas) mixture was smaller than the molecular mass of air $(28.97 \mathrm{~g} / \mathrm{mol})$. The main reason for this is that, in comparison with air, the volume concentration of $\mathrm{CO}$, the molecular mass of which is smaller than that of air, increased in smoke (gas).

Dynamic viscosities of smoke (gas) gaseous components were calculated at $37{ }^{\circ} \mathrm{C}$. Knowing the dynamic viscosities of smoke (gas) components, dynamic viscosity of the smoke (gas) mixture was calculated [19-22]. The diameter of particulate matter that was removed at $50 \%$ efficiency $\left(d_{50}\right)$ from $37{ }^{\circ} \mathrm{C}$ smoke (gas) was established. $d_{50}(\mu \mathrm{m})$ was calculated in accordance with Equation (1), reference point-efficiency of cyclonic separation when air temperature is equal to $20.0^{\circ} \mathrm{C}$. The same calculations were made for cases $2-4$.

In the second case, when gas temperature was $37^{\circ} \mathrm{C}$, concentration of $\mathrm{CO}$ was $17,000 \mathrm{mg} / \mathrm{m}^{3}$, concentration of $\mathrm{O}_{2}$ was $20.80 \%$, and $\mathrm{NO}$ concentration was $1200 \mathrm{mg} / \mathrm{m}^{3}$, the calculated concentration of $\mathrm{CO}_{2}$ was $0.13505 \%$. The calculated molecular mass of the smoke (gas) mixture was $28.962 \mathrm{~g} / \mathrm{mol}$. 
In the third case, when gas temperature was $37^{\circ} \mathrm{C}$, concentration of $\mathrm{CO}$ was $4000 \mathrm{mg} / \mathrm{m}^{3}$, concentration of $\mathrm{O}_{2}$ was $20.65 \%$, and $\mathrm{NO}$ concentration was $900 \mathrm{mg} / \mathrm{m}^{3}$, the calculate concentration of $\mathrm{CO}_{2}$ was $0.27975 \%$. The calculated molecular mass of the smoke (gas) mixture was $28.952 \mathrm{~g} / \mathrm{mol}$.

In the fourth case, when the gas temperature in the operating boiler reached $120^{\circ} \mathrm{C}$, the concentration of $\mathrm{CO}$ was $532.4 \mathrm{mg} / \mathrm{m}^{3}$, NO concentration was $352.1 \mathrm{mg} / \mathrm{m}^{3}$, concentration of $\mathrm{O}_{2}$ was $7.9 \%$, concentration of $\mathrm{CO}_{2}$ was $12.579 \%$. The calculated molecular mass of the smoke (gas) mixture was $30.451 \mathrm{~g} / \mathrm{mol}$.

\section{Results and Discussion}

In order to properly evaluate the gas purification efficiency, it is imperative to analyze the aerodynamic processes occurring inside the cyclone. The most efficient of the examined cyclones-the three-level eight-channel cyclone, having an air flow distribution rate in its channels equal to 75/25-was chosen to evaluate efficiency changes. In this position, air flow velocity values in channels are analyzed when the average velocity in the cyclone is equal to $16 \mathrm{~m} / \mathrm{s}$.

\subsection{Analysis of Gas Flow Velocity Distribution in Channels of the Three-Level Cyclone-Separator}

By adjusting the inner position of the cyclone's half-rings in such a way that the transit air flow value was 50\% less than that of the peripheral flow (75/25 air volume distribution rate), and the average velocity in the cyclone was $16 \mathrm{~m} / \mathrm{s}$, the highest air flow velocity was measured at the last measurement point of the third level's first channel. In the beginning of the third level's first channel, velocity was equal to $13.4 \mathrm{~m} / \mathrm{s}$, and it increased by 2.25 times in the end, reaching a peak value of $29.5 \mathrm{~m} / \mathrm{s}$ (Figure 3). A tendency of increase in the first channel can also be observed in the first level. Velocity increased because the first channel was four times wider in the beginning, compared to the end, and while the flowing air flow volume was maintained at the same level, velocity increased 2.25 times.

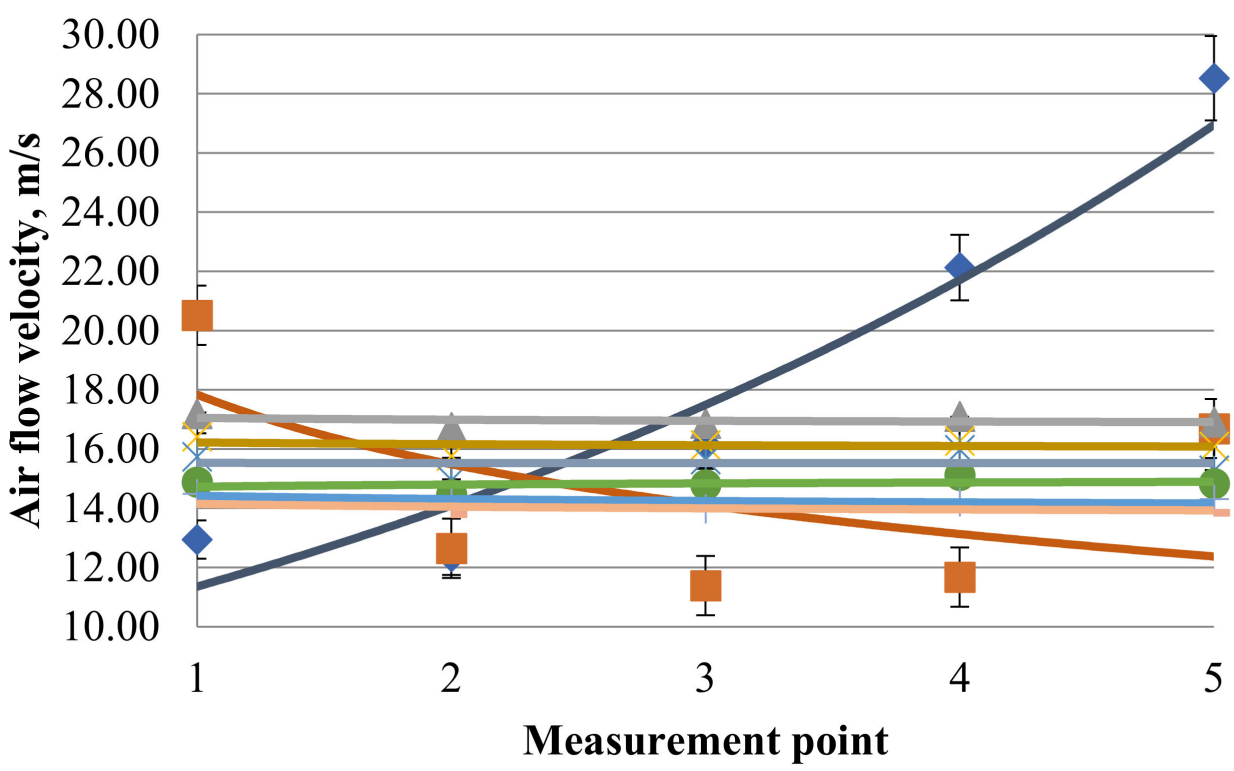

1st channel 2nd channel $\triangle$ 3rd channel 4th channel $* 5$ th channel 6th channel +7 th channel - 8th channel

Figure 3. Air flow velocity distribution in the channels in the three-level eight-channel cyclone, when the air flow distribution rate is $75 / 25$ and the average velocity in the cyclone is $16 \mathrm{~m} / \mathrm{s}$.

A decline in velocity was observed in the second to eighth channels in levels one to three, from the channel's beginning to the end, the decrease being $3-4 \%$. The velocity dropped in channels three to eight because flowing through the channel, the air flow was constantly touching the channel's walls and was affected by the force of friction. It 
can be concluded that a decline in air flow velocity occurred due to the influence of the peripheral air flow. The peripheral air flow, flowing back to the previous channel, clashed with the onward-flowing air flow, and filtration occurred. The filtering air flows stopped one another, thus yielding a decline in air flow velocity.

The longer the air flow path is inside the channel, the more it is affected by friction, thus a larger decline in velocity was observed in the third channel. The velocity declined in the second channel because air flow, with a velocity of $29 \mathrm{~m} / \mathrm{s}$, flowed from the first channel, and the average velocity saw an increase in the beginning of the second channel. Starting from the third channel, velocity constantly dropped in consequent channels. The change of average velocity between the third and fourth channels of the first level was measured to be $0.9 \mathrm{~m} / \mathrm{s}$. It was also measured to be $0.9 \mathrm{~m} / \mathrm{s}$ in the second level, and $0.8 \mathrm{~m} / \mathrm{s}$ in the third one. A similar tendency was observed is consequent channels. From the third channel onward the widths in each channel remained to be the same, this is why the same air flow, affected by aerodynamic resistance, was flowing. A decline in velocity happened due to the effect of the dynamic resistance. The velocity in the channels of three levels was different. The average velocity in channels of the second level was $0.3 \mathrm{~m} / \mathrm{s}$ higher than the average velocity in the first level $(15.4 \mathrm{~m} / \mathrm{s})$, while the average velocity in the third level was $0.6 \mathrm{~m} / \mathrm{s}$ higher than in the second level. The biggest difference was observed between the eighth channel of the first and second levels, which was equal to $1.1 \mathrm{~m} / \mathrm{s}$. Air flow velocity was highest in the third level because air from the second level must pass through ducts, connecting both levels of the cyclone, before exiting the cyclone.

The results for the experimental tests on the impact of smoke (gas) and temperature on aerodynamic resistance in the newly designed eight-channel cyclone are presented in Figure 4.

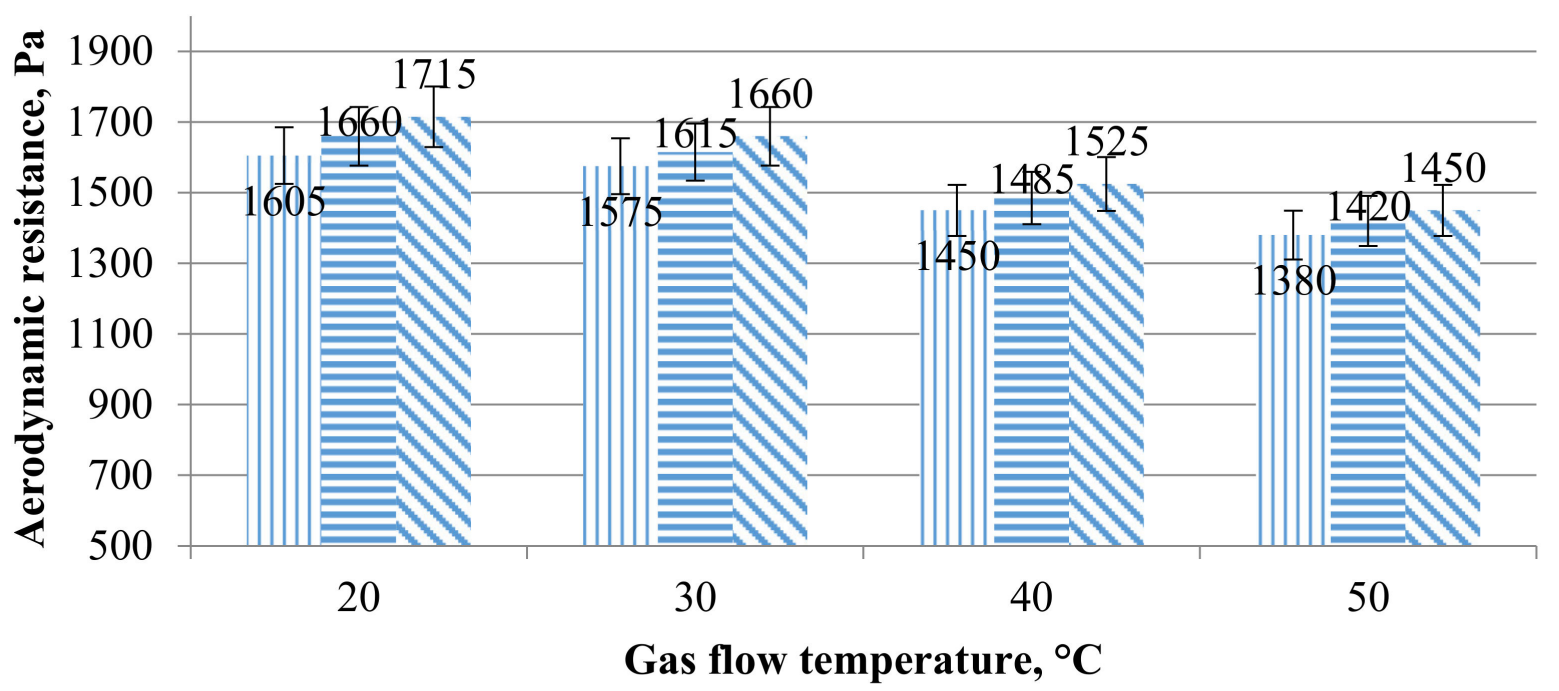

II I level cyclone = II level cyclone : III level cyclone

Figure 4. Dependency of aerodynamic resistance on the temperature of smoke (gas) temperature in one-, two- and three-level cylindrical eight-channel cyclones with curvilinear half-rings, at 75/25 flow distribution rate, the average velocity inside the cyclone being $16 \mathrm{~m} / \mathrm{s}$.

According to the research results of smoke's (gas') impact on the aerodynamic resistance in an eight-channel cyclone with curvilinear half-rings, at a 75/25 flow distribution rate, it can be stated that smoke's (gas') composition only slightly influences the cyclone's aerodynamic resistance. When the smoke (gas) temperature increases from $20{ }^{\circ} \mathrm{C}$ to $50{ }^{\circ} \mathrm{C}$, the aerodynamic resistance dropped from 1605 to $1380 \mathrm{~Pa}$ in the one-level eight-channel 
cylindrical cyclone, 1660 to $1420 \mathrm{~Pa}$ in the two-level eight-channel cylindrical cyclone, and $1715 \mathrm{~Pa}$ to $1450 \mathrm{~Pa}$ in the three-level eight-channel cylindrical cyclone (Figure 4). The reason for a decline in aerodynamic resistance is the declining gas density. When the air temperature was $20^{\circ} \mathrm{C}$, the density was equal to $1.189 \mathrm{~kg} / \mathrm{m}^{3}, 30^{\circ} \mathrm{C}$, the density was equal to $1.15 \mathrm{~kg} / \mathrm{m}^{3}, 40{ }^{\circ} \mathrm{C}$, the density was equal to $1.114 \mathrm{~kg} / \mathrm{m}^{3}$, and at $50{ }^{\circ} \mathrm{C}$, the density was equal to $1.078 \mathrm{~kg} / \mathrm{m}^{3}$.

\subsection{Theoretical Evaluation of Aerodynamic Parameters}

Theoretical aggressive gas flow studies were conducted at various temperatures and humidity conditions. Empirical expressions were selected to achieve the highest accuracy results.

According to the obtained theoretical results, a specially adapted mathematical expression (Equation (3)) has been created to determine the relation of gas flow velocity to the relative humidity of the aggressive gas flow.

$$
U_{1}=x_{2} \cdot \varphi+y_{2}
$$

Here, $U_{1}$-aggressive gas flow velocity in the cyclone, $\mathrm{m} / \mathrm{s} ; \varphi$-relative humidity of aggressive gas flow, \%. This expression can be used when the aggressive gas flow relative humidity $\varphi=0-95 \%, x_{1}$-the first variable of velocity, $\mathrm{m} /(\mathrm{s} \cdot \%) ; y_{1}$-the second variable of velocity, $\mathrm{m} / \mathrm{s}$. Therefore, if $t=20^{\circ} \mathrm{C}, x_{1}=-0.0008, y_{1}=12.04 ;$ if $t=37{ }^{\circ} \mathrm{C}, x_{1}=0.0220$, $y_{1}=12.3815$; if $t=50^{\circ} \mathrm{C}, x_{1}=0.0046, y_{1}=12.6467$; if $t=100{ }^{\circ} \mathrm{C}, x_{1}=0.0296, y_{1}=13.446$; if $t=120^{\circ} \mathrm{C}, x_{1}=-0.0860, y_{1}=13.8246$; and if $t=200{ }^{\circ} \mathrm{C}, x_{1}=-0.5482, y_{1}=15.3022$.

Information on the change of relative humidity of aggressive gas flow at a low (up to $50{ }^{\circ} \mathrm{C}$ ) temperature has been found in the literature [23-28]. The newly designed, multichannel cyclone can be operated at temperatures above $100{ }^{\circ} \mathrm{C}$, so the available data are insufficient. Theoretical studies were performed and the results were allowed to form an approximate mathematical expression (Equation (6)), which describes the change of the relative humidity of the aggressive gas flow at a gas flow temperature higher than $100{ }^{\circ} \mathrm{C}$ :

$$
\varphi_{\text {g.f. }}=1285.6 \cdot e^{-0.027 \cdot t_{g . f .}, \%}
$$

where $\varphi_{\text {g.f. }}$-a relative humidity of the gas flow, $\% ; t_{g . f .}$-a temperature of the gas flow, ${ }^{\circ} \mathrm{C}$; and $e=2.718$.

The special conditions affect the density of the gas flow, which is closely related to the viscosity and determines the nature of the flow in the new design cyclone channels. A simplified case was chosen for the theoretical calculation, when the gas flow consisted of a mixture of air and water vapor.

Theoretical expressions were chosen to form the theoretical expression of the density of the aggressive gas flow. The sensitivity analysis showed that the lowest mean error was obtained between the density and relative humidity of the aggressive gas flow, i.e., at a temperature of $50{ }^{\circ} \mathrm{C}$, when error was equal to $\pm 0.24{ }^{\circ} \mathrm{C}$. Based on the obtained results, Equation (1) can be specially adapted to calculate the density of the aggressive gas in a simpler expression (Equation (7)):

$$
\rho_{g . f .}=x_{2} \cdot \varphi_{g . f .}+y_{2}
$$

where $\rho_{g . f}$ - density of gas flow, $\mathrm{kg} / \mathrm{m}^{3} ; \varphi_{g . f}$-relative humidity of gas flow, $\% ; x_{2}-1$ st variable of density; $y_{2}-2$ nd variable of density. Therefore, if $t_{\text {g.f. }}=20{ }^{\circ} \mathrm{C}, x_{2}=0.0002$, $y_{2}=1.2048$; if $t_{\text {g.f. }}=37^{\circ} \mathrm{C}, x_{2}=0.0005, y_{2}=1.1425$; if $t_{\text {g.f. }}=50{ }^{\circ} \mathrm{C}, x_{2}=0.0008, y_{2}=1.093$; if $t_{\text {dg.f. }}=100{ }^{\circ} \mathrm{C}, x_{2}=0.0061, y_{2}=0.946$; if $t_{\text {g.f. }}=120{ }^{\circ} \mathrm{C}, x_{2}=0.0150, y_{2}=0.9061$; and if $t_{\text {g.f. }}=200{ }^{\circ} \mathrm{C}, x_{2}=0.0809, y_{2}=0.7463$.

The accuracy of the calculation was determined using the values of the relative humidity of different gas flows. The deviation applied for Equation (7) ranged from $-0.22 \%$ (when $\left.\varphi_{\text {g.f. }}=95 \%\right)$ to $+0.02 \%\left(\right.$ when $\left.\varphi_{\text {g.f. }}=0 \%\right)$. 


\subsection{Theoretical Evaluation of Impact of the Gas (Air) Temperatures and Smoke (Gas) on the Purification Efficiency of the Multi-Channel Cyclone}

Formulas that allow the evaluating of the influence of the gaseous components on cyclonic separation efficiency have not been discovered in the scientific literature. An empirical formula, which allows the calculation of the polydisperse particulate matter's separation from the air flow in a multi-channel cyclone [11], depending on the number of channels, has been proposed:

$$
\varepsilon=\frac{1}{1+2^{n-1}}
$$

where $n-$ number of channels in a multi-channel cyclone; and $\varepsilon-P M$ expulsion coefficient. The cyclonic separation efficiency (in percent), E, equals $100-\varepsilon$. The particulate matter used in this study was smaller than $20 \mu \mathrm{m}$, so the calculated separation efficiency would be lower than in the case of the polydisperse flow.

It can be seen that an increase in the number of channels also yields an increase in the efficiency of air purification (Equation (8)). The theoretical air purification efficiency of the eight-channel cylindrical cyclone $(n=8)$, used in experimental trials, is $99.2 \%$, according to Equation (8). The results of the experimental smoke (gas) impact on the efficiency in an eight-channel wood ash separation, one to three level cylindrical cyclone are presented in Figure 5. During experimental trials, maximum air purification efficiency values, such as removing a 0-20 $\mu \mathrm{m}$ diameter of wood ash particles from the air (air temperature being $20{ }^{\circ} \mathrm{C}$ ), have been obtained: using a one-level eight-channel cyclone- $84.2 \%$; using the twolevel eight-channel cyclone- $84.6 \%$; and using a three-level eight-channel cyclone- $84.9 \%$; the average air flow velocity being $16 \mathrm{~m} / \mathrm{s}$ (Figure 3). The experimentally determined eight-channel cylindrical cyclone's separation efficiency was lower than the one calculated using Equation (8) because wood combustion in boiler houses creates ash particles, not only smaller than $20 \mu \mathrm{m}$, but that can also be larger [3,29]. In order to measure the gaseous components' impact on an eight-channel, one to three level, multi-channel cyclone with adjustable curvilinear half-rings on efficiency, while removing wood ash particles smaller than $20 \mu \mathrm{m}$, a smoke (gas) source was created by burning wood and additionally introducing wood ash to the air duct after the ventilator along the flow direction, using a sprayer, connected to a compressor, creating a 10 bar compressed air flow. During wood combustion, the highest concentration change from measured gaseous components $(\mathrm{CO}$, $\mathrm{CO}_{2}, \mathrm{NO}, \mathrm{NO}_{2}$ and $\mathrm{O}_{2}$ ) was attributed to $\mathrm{CO}$, this is why the $\mathrm{CO}$ concentration has been attributed to the $x$ axis.

The efficiency of removing wood ash particles smaller than $20 \mu \mathrm{m}$ from smoke (gas) in the one-level cylindrical eight-channel cyclone with curvilinear half-rings, having a 75/25 flow distribution rate, when the average velocity inside the cyclone corresponds with the maximum efficiency-16 m/s-gradually decreased from $84.2 \%$ to $79.7 \%$ when the CO concentration was increased from 0 to $31 \mathrm{~g} / \mathrm{m}^{3}$ (Figure 5). Differences in the efficiency of removing wood ash particles smaller than $20 \mu \mathrm{m}$ in a cyclone, when the CO concentration was 0 and $4 \mathrm{~g} / \mathrm{m}^{3}, 4$ and $17 \mathrm{~g} / \mathrm{m}^{3}$ or 17 and $31 \mathrm{~g} / \mathrm{m}^{3}$, are statistically unreliable; only the tendency of decline in air purification efficiency, when the $\mathrm{CO}$ concentration was being increased, was monitored.

Differences in the efficiency of removing wood ash particles smaller than $20 \mu \mathrm{m}$ in the two-level cyclone, when the CO concentration was 0 and $4 \mathrm{~g} / \mathrm{m}^{3}, 4$ and $17 \mathrm{~g} / \mathrm{m}^{3}$ or 17 and $31 \mathrm{~g} / \mathrm{m}^{3}$, are statistically unreliable; only the tendency of decrease in gas purification efficiency, when the CO concentration was being increased, was monitored. It can be assumed that the reason for the efficiency decline in removing wood ash from air in a multi-channel cylindrical cyclone, during an increase in CO concentration in smoke (gas), was the increasing smoke (gas) viscosity, compared to clean air (Figure 5). 


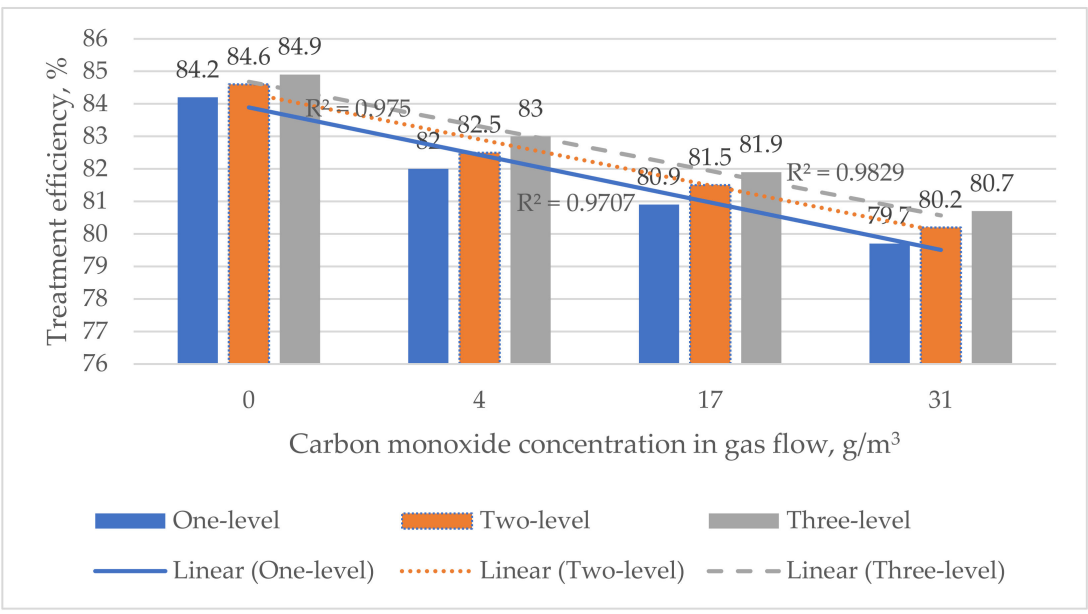

Figure 5. The dependency of the removal efficiency on the carbon monoxide concentration in the flow, while removing wood ash particles smaller than $20 \mu \mathrm{m}$ from gas in a one-level cylindrical eight-channel cyclone with curvilinear half-rings, having a 75/25 flow distribution rate, when the average velocity inside the cyclone is $16 \mathrm{~m} / \mathrm{s}$.

The efficiency of removing wood ash particles smaller than $20 \mu \mathrm{m}$ from smoke (gas) in the three-level cylindrical eight-channel cyclone gradually decreased from $84.9 \%$ to $80.7 \%$, when the $\mathrm{CO}$ concentration was increased from 0 to $31 \mathrm{~g} / \mathrm{m}^{3}$. Differences in the efficiency of removing wood ash particles smaller than $20 \mu \mathrm{m}$ in a device was monitored.

The results obtained can only be compared relatively with other prototypes, as both the efficiencies and the influence of gaseous pollutants are different. For example, the treatment efficiency of a four- and six-channel cyclone-separator, at a $0 \mathrm{~g} / \mathrm{m}^{3}$ of $\mathrm{CO}$ average, is equal to $69.3 \%$ and $82.1 \%$, respectively. The effect of $\mathrm{CO}$ on particulate matter trapping remains similar regardless of the design of the multi-channel cyclone-separator. The treatment efficiency ratios are 0.82:0.97:1.00 for the four-channel: six-channel: eight-channel cyclone, respectively, provided that the gas flow rates and capacities are the same in these devices.

In order to theoretically estimate the influence of air temperature upon the cyclone separation efficiency, a case, when wood ash is removed from air with a different temperature, was theoretically analyzed. A change in the air's dynamic viscosity, which influences the cyclonic separation efficiency, occurs with temperature change. Values of dynamic air viscosity and $\mathrm{d}_{50}$ at $20-120^{\circ} \mathrm{C}$ temperatures are presented in Figure 6.

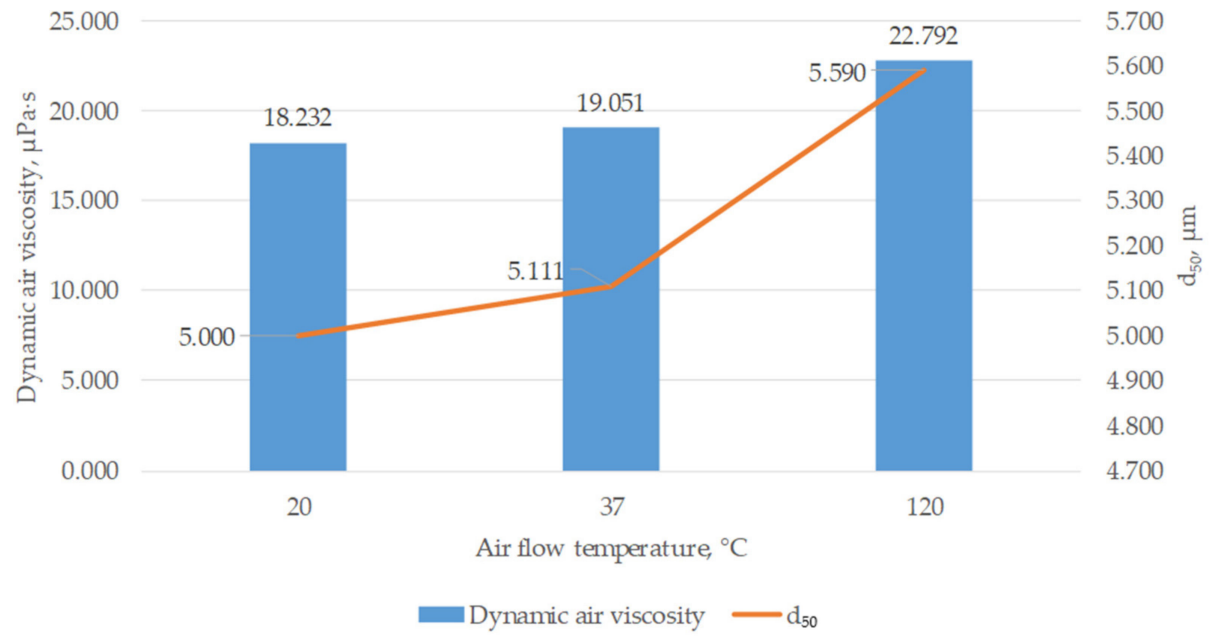

Figure 6. Values of dynamic air viscosity and treatment efficiency of particulate matter $\left(d_{50}\right)$ values at $20-120^{\circ} \mathrm{C}$ air temperatures. 
As we can see in Figure 6, an increase in air temperature yields an increase in dynamic viscosity values. Knowing values of dynamic air viscosity, the $\mathrm{d}_{50}$ value can be calculated, which equals to a $50 \%$ particulate matter separation efficiency in the cyclone, according to Equation (1). $\mathrm{d}_{50}$ values at $37^{\circ} \mathrm{C}$ and $120{ }^{\circ} \mathrm{C}$ temperature have been calculated, with the $20^{\circ} \mathrm{C}$ air temperature as a reference point. It has been theoretically calculated that an increase in air temperature from $20^{\circ} \mathrm{C}$ to $37^{\circ} \mathrm{C}$ yields an increase in the $\mathrm{d}_{50}$ value from 5.0 to $5.111 \mu \mathrm{m}$, i.e., $2.22 \%$, while an increase in air temperature from $20{ }^{\circ} \mathrm{C}$ to $120{ }^{\circ} \mathrm{C}$ yields an increase in the $\mathrm{d}_{50}$ value up to $5.59 \mu \mathrm{m}$, i.e., $11.8 \%$. The overall air purification efficiency, removing 0-20 $\mu \mathrm{m}$ of wood ash particles, decreases with an increase in temperature because of an increase in dynamic air viscosity, meaning the cyclone will remove larger particles. It is difficult to derive a direct dependency between $\mathrm{d}_{50}(\mu \mathrm{m})$ and $\mathrm{E}(\%)$ in an eight-channel cyclone; however, according to theoretical and experimental trial data, it can be stated that an increase in air temperature yields a decrease in wood ash removal efficiency. In order to estimate the $d_{50}$ value at a certain temperature, it is of uttermost importance to determine the empirical correlation between $d_{50}$ and air temperature. The correlation between $d_{50}$ and air temperature when capturing particulate matter at temperatures in the interval of 20-120 ${ }^{\circ} \mathrm{C}$ can be described, according to the following empirical formula:

$$
y=4.6758 \mathrm{e}^{0.0558 \mathrm{x}}
$$

where $\mathrm{x}$ - air temperature, ${ }^{\circ} \mathrm{C} ; \mathrm{y}-\mathrm{d}_{50} \mu \mathrm{m}$; $\mathrm{d}_{50}-50 \%$ of particulate matter removal efficiency in the new design multi-channel cyclone.

This empirical formula is suitable to describe the dependency of $d_{50}$ on air temperature (in the measured temperature interval) because it corresponds with a high correlation coefficient's value $\left(\mathrm{R}^{2}=0.891\right)$. In order to theoretically estimate the impact of smoke (gas) components on the efficiency of the removal of wood ash particles smaller than $20 \mu \mathrm{m}$ in a cylindrical eight-channel cyclone with curvilinear half-rings, having a 75/25 flow distribution rate, $\mathrm{d}_{50}$ calculations have been made. Results of these calculations are presented in Table 1.

As we can see in Table 1 , the $\mathrm{d}_{50}$ value is $1.94 \%$ higher, when the temperature is $37^{\circ} \mathrm{C}$ and the $\mathrm{CO}$ concentration in smoke (gas) is $4 \mathrm{~g} / \mathrm{m}^{3}$, than when particulate matter is removed at a $20{ }^{\circ} \mathrm{C}$ air temperature. When the $\mathrm{CO}$ concentration rises to $31 \mathrm{~g} / \mathrm{m}^{3}$, the $\mathrm{d}_{50}$ value increases only slightly-up to $5.098 \mu \mathrm{m}$. In the case when the smoke (gas) temperature in the boiler house, stoked by wood, reaches $120{ }^{\circ} \mathrm{C}$, the $\mathrm{CO}$ concentration is $532.4 \mathrm{mg} / \mathrm{m}^{3}$, the NO concentration is $352.1 \mathrm{mg} / \mathrm{m}^{3}$, the $\mathrm{O}_{2}$ concentration in smoke is $7.9 \%$, and the $d_{50}$ increases up to $5.449 \mu \mathrm{m}$, resulting in a lower efficiency of the particulate matter's removal. Two factors have an impact—smoke (gas) temperature and the composition and concentration of gaseous components that make up smoke (gas). Gaseous combustion components expelled in air during wood combustion, having a dynamic viscosity lower than $19.051 \cdot 10^{-6} \mathrm{~Pa} \cdot \mathrm{s}$, with the temperature being $37^{\circ} \mathrm{C}$, decrease the $\mathrm{d}_{50}$ value, at the same time as increasing the efficiency of the particulate matter's removal in the cyclone, i.e., this impact is attributed to $\mathrm{CO}_{2}$ and $\mathrm{CO}$. The value of the impact also depends on the concentration of gaseous components in the smoke (gas) mixture. Other gaseous components, having a dynamic viscosity higher than $19.051 \cdot 10^{-6} \mathrm{~Pa} \cdot \mathrm{s}$, increase the viscosity of the mixture. Such an impact can be attributed to $\mathrm{O}_{2}$ and $\mathrm{NO}$; however, the $\mathrm{O}_{2}$ concentration decreases during combustion.

Smoke (gas) consists not only from nitrogen, carbon, and sulfur oxides, but also water vapor. Water vapor can create conditions for coagulation in finely divided particles when larger solid particles are formed. This is the reason why it is difficult to unambiguously estimate the smoke's (gas') impact on solid particle removal efficiency in the cyclone.

Strict environmental requirements have to be followed while exploiting air purification devices-the allowed PM concentration depends on the nominal thermo power of the solid fuel boiler. When the nominal thermo power of the boiler is less than $20 \mathrm{MW}$, but more than $1 \mathrm{MW}$, the threshold value of particulate matter is $800 \mathrm{mg} / \mathrm{m}^{3}$. When the boiler's nominal thermo power is less than $1 \mathrm{MW}$, the threshold value of particulate matter is $700 \mathrm{mg} / \mathrm{m}^{3}$ 
for a new device and $400 \mathrm{mg} / \mathrm{m}^{3}$ for a currently exploited device, when the standard $\mathrm{O}_{2}$ concentration is $6 \%$ (volume), according to LAND 43-2013.

It is possible to decrease the PM concentration in gas down to $<0.8 \mathrm{~g} / \mathrm{m}^{3}$, using an eight-channel cyclone with adjustable half-rings, when the initial 0-20 $\mu \mathrm{m}$ wood ash concentration in gas is $5 \mathrm{~g} / \mathrm{m}^{3}$. Threshold values, determined by LAND 43-2013, were reached because, during experimental trials, only 0-20 $\mu \mathrm{m}$ size particles were used, while larger particles emerged during biofuel combustion in boiler houses. The values of Pearson's coefficient, estimating the correlation between air density and aerodynamic resistance, have been calculated. The Pearson's coefficient for the one-level cyclone equals 0.973 , for the two-level cyclone equals 0.981 , and for the three-level cyclone equals 0.985 . In all cases, similar Pearson's coefficient values, reaching almost 1, have been obtained, thus it can be stated that gas temperature affects the aerodynamic resistance of the cyclone.

\section{Conclusions}

1. The multi-channel cyclonic separation efficiency has been evaluated by calculating the efficiency of the traditional structure cyclone, additionally evaluating gaseous components' (pollutants) influence. When evaluating the efficiency of multi-channel cyclonic separation, the $d^{L}{ }_{50}$ value has been estimated - the diameter of solid particles, removed with a $50 \%$ probability, i.e., the diameter of solid particles, which are removed in the cyclone with a $50 \%$ probability. Air temperature influences the $d_{50}$ value; an increase in air temperature yields an increase in $d_{50}$ value, i.e., the overall particulate matter removal efficiency declines, the reason for this being an increasing dynamic air viscosity. At a $120^{\circ} \mathrm{C}$ temperature, the $\mathrm{d}_{50}$ value is approximately $11.8 \%$ higher than at an air temperature of $20{ }^{\circ} \mathrm{C}$

2. Theoretical expressions of the velocity and density of the aggressive gas flow in the channel of the new design of a cyclone, depending on the temperature and humidity, were specially adapted. An accuracy of the calculated velocity is equal to $-0.01 \%$, when the humidity of the gas flow is $95 \%$, and up to $+0.05 \%$ when humidity is $50 \%$. A change in the relative humidity of the aggressive gas flow at temperatures above $100{ }^{\circ} \mathrm{C}$ was analyzed. An approximate mathematical expression was formed and taken error was equal to $\pm 0.24{ }^{\circ} \mathrm{C}$. An accuracy of the calculated density of the aggressive gas flow is equal to $-0.22 \%$, when humidity of gas flow is $95 \%$, and up to $+0.02 \%$ when humidity is $0 \%$.

3 . The $y=4.6758 \cdot e^{0.0558 x}$ empirical formula can be used to determine the correlation between the $d_{50}$ value and air temperature when removing particulate matter in a new generation multi-channel cyclone, the temperature interval being $20-120^{\circ} \mathrm{C}$. This empirical formula is very suitable to describe the correlation between the $d_{50}$ value and air temperature (in the analyzed temperature interval) because it corresponds to a high correlation coefficient value $\left(R^{2}=0.891\right)$.

4. At $37^{\circ} \mathrm{C}$ temperature in a multi-channel cyclone, the diameter of solid particles removed from smoke (gas) is $2.22 \%$ higher than when removing solid particles from $20^{\circ} \mathrm{C}$ temperature air, this is why the overall particulate matter removal efficiency is lower. Two factors have influence-smoke (gas) temperature and the composition and concentration of gaseous components present in the smoke (gas) mixture. Gaseous components, present in the smoke (gas) mixture, with the dynamic viscosity lower than that of the same temperature air, decrease the $d_{50}$ value whilst simultaneously increasing the overall particulate matter removal efficiency in the cyclone, i.e., this effect is attributed to $\mathrm{CO}_{2}$ and $\mathrm{CO}$, while $\mathrm{O}_{2}$ and NO have the opposite effect. The cyclonic separation efficiency drops by approximately $4.4 \%$ when the concentration of carbon monoxide is increased in the smoke from 0 to $31 \mathrm{~g} / \mathrm{m}^{3}$ because the dynamic viscosity of the smoke increases. If the $\mathrm{CO}$ concentration increases, the $\mathrm{O}_{2}$ concentration increases as well, while the $\mathrm{CO}_{2}$ concentration declines. $\mathrm{O}_{2}$ dynamic viscosity is lower than that of gas, whereas $\mathrm{CO}_{2}$ and $\mathrm{CO}$ have a dynamic viscosity lower than that of air. Therefore, the effect is not strongly expressed.

5. With an increase in the smoke (gas) temperature from $20^{\circ} \mathrm{C}$ to $50^{\circ} \mathrm{C}$, the aerodynamic resistance in the one-level eight-channel cylindrical cyclone drops from $1605 \mathrm{~Pa}$ to 
$1380 \mathrm{~Pa}$, from $1660 \mathrm{~Pa}$ to $1420 \mathrm{~Pa}$ in the two-level eight-channel cylindrical cyclone, and the pressure drop is equal to $265 \mathrm{~Pa}$ in the three-level eight-channel cylindrical cyclone. The reason for a decline in aerodynamic resistance is the declining gas density.

\section{Patents}

Baltrènas, P., \& Chlebnikovas, A. (2019). Cylindrical Multi-Level Multi-Channel Cyclone-Filter (Patent No. EP 2886182 B1).

Author Contributions: Conceptualization, A.C. and D.P.; methodology, A.C., D.P., K.K. and A.K.; software, A.C.; validation, A.C., D.P., K.K. and A.K.; formal analysis, A.C., D.P., K.K. and A.K.; investigation, A.C. and D.P.; resources, A.C., D.P., K.K. and A.K.; data curation, A.C. and D.P.; writing-original draft preparation, A.C. and D.P.; writing-review and editing, A.C. and D.P.; visualization, A.C. and D.P.; supervision, A.C. and D.P.; project administration, A.K.; funding acquisition, A.K. All authors have read and agreed to the published version of the manuscript.

Funding: This research received no external funding.

Informed Consent Statement: Not applicable.

Data Availability Statement: Not applicable.

Conflicts of Interest: The authors declare no conflict of interest.

\section{References}

1. Rajabi, H.; Hadi Mosleh, M.; Mandal, P.; Lea-Langton, A.; Sedighi, M. Emissions of Volatile Organic Compounds from Crude Oil Processing_Global Emission Inventory and Environmental Release. Sci. Total Environ. 2020, 727, 138654. [CrossRef] [PubMed]

2. Talbi, K.; Nemouchi, Z.; Donnot, A.; Belghar, N. An Experimental Study and a Numerical Simulation of the Turbulent Flow under the Vortex Finder of a Cyclone Separator. J. Appl. Fluid Mech. 2011, 4, 69-75.

3. Baltrènas, P.; Chlebnikovas, A. Removal of Fine Solid Particles in Aggressive Gas Flows in a Newly Designed Multi-Channel Cyclone. Powder Technol. 2019, 356, 480-492. [CrossRef]

4. Baltrènas, P.; Chlebnikovas, A. Cylindrical Multi-Level Multi-Channel Cyclone-Filter; European Patent Office: Munich, Germany, 2013; pp. 1-16.

5. Vekteris, V.; Strishka, V.; Ozarovskis, D.; Mokshin, V. Experimental Investigation of Processes in Acoustic Cyclone Separator. Adv. Powder Technol. 2014, 25, 1118-1123. [CrossRef]

6. Vekteris, V.; Tetsman, I.; Mokshin, V. Investigation of the Efficiency of the Lateral Exhaust Hood Enhanced by Aeroacoustic Air Flow. Process Saf. Environ. Prot. 2017, 109, 224-232. [CrossRef]

7. Baltrènas, P.; Chlebnikovas, A. Investigation into the Aerodynamic Parameters of the Recently Designed Two-Level Cylindrical Multi-Channel Cyclone-Separator. Sep. Sci. Technol. 2015, 50, 1257-1269. [CrossRef]

8. Serebryanskyy, D.; Semeniuk, M.; Plashykhin, S. Research of Distribution of Concentration and Disperse Structure of Firm Particles in Gas Streams in System of Channels with the Closed Contours. Ind. Heat. Eng. 2013, 35, 83-92.

9. Vaitiekunas, P.; Petraitis, E.; Venslovas, A.; Chlebnikovas, A. Air Stream Velocity Modelling in Multichannel Spiral Cyclone Separator. J. Environ. Eng. Landsc. Manag. 2014, 22, 183-193. [CrossRef]

10. Tananaev, A.V. Inertial Filter-Separator; Russian Patent Office: Moscow, Russia, 1997; pp. 1-5.

11. Jakstoniene, I.; Serebryanskyy, D.; Vaitiekûnas, P. Experimental Research on the Work of Centrifugal Filter When Eliminating Solid Particles from Clinker Cooling System. In Proceedings of the 8th International Conference on Environmental Engineering, ICEE, Kitakyushu, Japan, 30 November-2 December 2011; Volume 1.

12. Li, Y.; Qin, G.; Xiong, Z.; Ji, Y.F.; Fan, L. The Effect of Particle Humidity on Separation Efficiency for an Axial Cyclone Separator. Adv. Powder Technol. 2019, 30, 724-731. [CrossRef]

13. Kang, Z.; Yuan, Q.; Zhao, L.; Dai, Y.; Sun, B.; Wang, T. Study of the Performance, Simplification and Characteristics of SNCR de-NOx in Large-Scale Cyclone Separator. Appl. Therm. Eng. 2017, 123, 635-645. [CrossRef]

14. Haake, J.; Oggian, T.; Utzig, J.; Rosa, L.M.; Meier, H.F. Investigation of the Pressure Drop Increase in a Square Free-Vortex Cyclonic Separator Operating at Low Particle Concentration. Powder Technol. 2020, 374, 95-105. [CrossRef]

15. Edelmann, D.; Móri, T.F.; Székely, G.J. On Relationships between the Pearson and the Distance Correlation Coefficients. Stat. Probab. Lett. 2021, 169, 108960. [CrossRef]

16. Djordjević, B.; Mane, A.S.; Krmac, E. Analysis of Dependency and Importance of Key Indicators for Railway Sustainability Monitoring: A New Integrated Approach with DEA and Pearson Correlation. Res. Transp. Bus. Manag. 2021, 41, 100650. [CrossRef]

17. Liu, C.; Zhang, Y.; Sun, L.; Gao, W.; Jing, X.; Ye, W. Influence of Indoor Air Temperature and Relative Humidity on Learning Performance of Undergraduates. Case Stud. Therm. Eng. 2021, 28, 101458. [CrossRef] 
18. Martínez-Mariño, S.; Eguía-Oller, P.; Granada-Álvarez, E.; Erkoreka-González, A. Simulation and Validation of Indoor Temperatures and Relative Humidity in Multi-Zone Buildings under Occupancy Conditions Using Multi-Objective Calibration. Build. Environ. 2021, 200, 107973. [CrossRef]

19. Poole, C.F.; Atapattu, S.N. Determination of Physicochemical Properties of Ionic Liquids by Gas Chromatography. J. Chromatogr. A 2021, 1644, 461964. [CrossRef] [PubMed]

20. Kartikawati, N.A.; Safdar, R.; Lal, B.; Mutalib, M.I.B.A.; Shariff, A.M. Measurement and Correlation of the Physical Properties of Aqueous Solutions of Ammonium Based Ionic Liquids. J. Mol. Liq. 2018, 253, 250-258. [CrossRef]

21. Patil, K.R.; Patil, S.K.; Shaikh, V.R.; Dagade, D.H.; Patil, K.J. Studies of Osmotic and Activity Coefficient Properties of Aqueous Solutions of Triethylammonium Formate and Triethylammonium Glycolate Protic Ionic Liquids at 298.15 K. J. Mol. Liq. 2021, 324, 115143. [CrossRef]

22. Guo, D.-S.; Li, X.-B.; Zhang, H.-N.; Li, F.-C.; Ming, P.-J.; Oishi, M.; Oshima, M. Experimental Study on the Characteristics of Temperature Dependent Surface/Interfacial Properties of a Non-Ionic Surfactant Aqueous Solution at Quasi-Thermal Equilibrium Condition. Int. J. Heat Mass Transf. 2022, 182, 122003. [CrossRef]

23. Yan, J.; Wang, H.; Zheng, Y.; Huang, X.; Meng, H.; Tan, C. A Novel Dew Point Measurement System Based on the Thermal Effect of Humidity Sensitive Thin Film. Measurement 2022, 187, 110248. [CrossRef]

24. Lv, J.; Xu, H.; Xu, T.; Liu, H.; Qin, J. Study on the Performance of a Unit Dew-Point Evaporative Cooler with Fibrous Membrane and Its Application in Typical Regions. Case Stud. Therm. Eng. 2021, 24, 100881. [CrossRef]

25. Lv, J.; Zhu, M.; Xu, H.; Wang, L.; Zhou, B. The Entransy Analysis in the Wet Channel of Dew Point Evaporative Cooler. J. Build. Eng. 2021, 44, 103371. [CrossRef]

26. Pumo, D.; Noto, L. V Exploring the Linkage between Dew Point Temperature and Precipitation Extremes: A Multi-Time-Scale Analysis on a Semi-Arid Mediterranean Region. Atmos. Res. 2021, 254, 105508. [CrossRef]

27. Troxel, T.R.; Gadberry, M.S.; Beck, P.A. Temperature, Relative Humidity, and Dew Point of 6 Commercial Trailer Compartments during Summer Transportations of Beef Calves in the Mid-South. Prof. Anim. Sci. 2016, 32, 461-469. [CrossRef]

28. Ismail, I.M.I.; Rashid, M.I.; Ali, N.; Altaf, B.A.S.; Munir, M. Temperature, Humidity and Outdoor Air Quality Indicators Influence COVID-19 Spread Rate and Mortality in Major Cities of Saudi Arabia. Environ. Res. 2022, 204, 112071. [CrossRef] [PubMed]

29. Chlebnikovas, A. Experimental Investigation of a One-Level Eight-Channel Cyclone-Separator Incorporating Quarter-Rings. Hem. Ind. 2021, 75, 241-251. [CrossRef] 